\title{
Significant linkage at chromosome 19q for otitis media with effusion and/or recurrent otitis media (COME/ROM)
}

\author{
Wei-Min Chen ${ }^{1,2}$, E Kaitlynn Allen ${ }^{1,3}$, Josyf C Mychaleckyj ${ }^{1,2}$, Fang Chen ${ }^{1}$, Xuanlin Hou' ${ }^{1}$, Stephen S Rich ${ }^{1,2,4}$, \\ Kathleen A Daly ${ }^{6}$ and Michèle M Sale $e^{1,4,5^{*}}$
}

\begin{abstract}
Background: In previous analyses, we identified a region of chromosome 19 as harboring a susceptibility locus for chronic otitis media with effusion and/or recurrent otitis media (COME/ROM). Our aim was to further localize the linkage signal and ultimately identify the causative variant or variants. We followed up our previous linkage scan with dense SNP genotyping across in a $5 \mathrm{Mb}$ region. A total of 607 individuals from 139 families, including 159 affected sib pairs and 62 second-degree affected relative pairs, were genotyped at 1,091 SNPs. We carried out a nonparametric linkage analysis, modeling marker-to-marker linkage disequilibrium.

Results: The maximum log of the odds (LOD) score increased to $3.75\left(P=1.6 \times 10^{-5}\right)$ at position $63.4 \mathrm{Mb}$, with a LOD-1 support interval between $61.6 \mathrm{Mb}$ and $63.8 \mathrm{Mb}$, providing significant evidence of linkage between this region and COME/ROM. The support interval contains over 90 known genes, including several genes involved in the inflammasome protein complex, a key regulator of the innate immune response to harmful exogenous or endogenous stimuli. Parametric linkage analysis suggests that for a sib of an affected individual, the recurrence risk of COME/ROM due to this linkage region is twice the recurrence risk in the population. We examined potential associations between the SNPs genotyped in this region and COME/ROM, however none provided evidence for association.
\end{abstract}

Conclusion: This study has refined the $19 \mathrm{q}$ region of linkage with COME/ROM, and association results suggest that the linkage signal may be due to rare variants.

Keywords: Linkage, fine mapping, otolaryngology

\section{Background}

Otitis media $(\mathrm{OM})$, or inflammation of the middle ear, represents a leading reason for physician visits by children and a major component of the pediatric healthcare burden [1]. A significant proportion of children who suffer from acute $\mathrm{OM}$ go on to experience either chronic otitis media with effusion (COME) or recurrent otitis media (ROM). COME/ROM can result in permanent hearing loss, tympanic membrane abnormalities, other infections such as meningitis, parental days lost from work, and other sequelae $[2,3]$.

\footnotetext{
* Correspondence: msale@virginia.edu

'Center for Public Health Genomics, University of Virginia, Charlottesville, VA 22908, USA

Full list of author information is available at the end of the article
}

Genetic factors play an important role in COME/ ROM susceptibility. COME/ROM aggregates in families [4-7], and first-degree relatives of COME/ROM patients have higher rates of otitis media than would be expected based on population rates [8]. Twin and triplet studies confirm the strong familial component of COME and ROM, with heritability estimates of 0.64-0.74 in monozygotic twins and 0.20-0.53 in dizygotic twins [9-13].

To date, two linkage studies for COME/ROM have been published but the loci identified in the two studies did not overlap. The first genome-wide linkage scan, conducted by our group [14], identified evidence of linkage to chromosomal regions on $10 \mathrm{q} 26$ and $19 \mathrm{q} 13$, and support for linkage on $3 p$ conditional on linkage at 10q and 19q. Casselbrant et al. identified linkage peaks on
C Biomed Central

(c) 2011 Chen et al; licensee BioMed Central Ltd. This is an Open Access article distributed under the terms of the Creative Commons Attribution License (http://creativecommons.org/licenses/by/2.0), which permits unrestricted use, distribution, and reproduction in any medium, provided the original work is properly cited. 
chromosome 17q12, 10q22, 7q33, 6p25, and 4p15 [15]. In order to localize the linkage signal on chromosome 19 and identify susceptibility genes for COME/ROM, we have conducted fine mapping across this region, and evaluated these SNPs for linkage and association.

\section{Methods}

\section{Subjects}

This study was conducted with Institutional Review Board approval at the University of Minnesota, Wake Forest University, and the University of Virginia, and adhered to the tenets of the Declaration of Helsinki. Subjects who had tympanostomy tube surgery for COME/ROM (probands) and their families were recruited for the study, which has been described previously $[8,14,16]$. An otolaryngologist performed an ear examination to determine presence of $\mathrm{OM}$ sequelae without knowledge of the subject's prior OM history. In addition, tympanometric testing was performed in subjects at three frequencies $(226,630$ or 710 , and 1400 $\mathrm{Hz}$ ) to detect abnormal middle ear mechanics, and hearing was screened at $20 \mathrm{~dB}$ for speech frequencies. The current analyses included all subjects from the initial linkage scan of Daly et al. ( [14], with the addition of six new families rascertained and recruited using the same criteria [14]. A total of 607 individuals from 139 families, including 159 affected sib pairs and 62 seconddegree affected relative pairs, were used in analyses.

\section{SNP selection and genotyping}

We selected 1,536 SNPs for genotyping, including 1,492 chromosome 19 SNPs chosen from a combination of tagging, nonsynonymous and synonymous coding SNPs, physical coverage, and putative copy number variation (CNV) interrogation. Forty-four Ancestry Informative Markers (AIMs) spaced across the genome were included to verify major ethnic group membership and to detect European stratification in the families. Genotyping was carried out by the Center for Inherited Disease Research (CIDR) using Illumina's GoldenGate assay [17].

\section{Statistical analyses}

After removal of SNPs on the basis of poor genotype quality, missing data, excessive replicate and/or Mendelian errors [18-20], or monomorphic status, 1,091 SNPs were available for analyses. Deviations from Hardy Weinberg Equilibrium (HWE) in 223 unrelated individuals were determined using the exact test [18], and all SNPs were in Hardy-Weinberg equilibrium (P > 0.0001). Two monozygotic (MZ) twin pairs were detected and incorporated in the analysis. The computer program package Merlin [20] was used to identify and resolve inconsistencies within families.
The Kong and Cox linear nonparametric linkage (NPL) method [21] as implemented in Merlin was used for the NPL linkage analysis. Marker-marker linkage disequilibrium (LD) was modeled in the linkage analysis using the maximum-likelihood clustered marker approach [22] implemented in Merlin with thresholds of $r^{2}>0.5$ and $r^{2}>0.2$. We also explored other strategies to take into account the potential impact of LD on the validity of our linkage findings. We analyzed a subset of 90 families (out of 139 families in total) in which all affected individuals have complete parental data. This subset of data is expected to be free of the LD effect on linkage [22].

The Linkage and Association Modeling in Pedigrees (LAMP) method [23] was used for the parametric linkage analysis. In contrast to other parametric linkage methods, the LAMP method does not require the specification of the genetic model of the disease, and parameters such as the penetrance of each genotype (probability of affected status given genotype) and the frequency of the disease susceptibility allele can be estimated from the data.

In order to investigate whether the support for linkage on chromosome 19q can be explained by a common genetic variant in the region, we applied three familybased association tests, the Transmission/Disequilibrium Test (TDT) [24], the Generalized Disequilibrium Test (GDT) [25], and the more powerful Quasi-Likelihood Score test $\mathrm{M}_{\mathrm{QLS}}$ [26]. The TDT method examines the allele transmission disparity from heterozygote parents to their affected offspring. Although the TDT is viewed as the standard of family-based association tests, the presence of linkage without allelic association can result in an inflated false positive rate [27]. The GDT method generalizes the comparison between parent and offspring to all discordant relative pairs, including those families with incomplete parental data that cannot be handled in the standard TDT method. The GDT method also allows the adjustment of linkage in the association analysis. We included sex as a covariate and incorporated the identical-by-descent (IBD) statistics in the GDT analysis. The $\mathrm{M}_{\mathrm{QLS}}$ method also incorporates association evidence across families and has been shown to be more powerful in many settings than standard methods. The prevalence of otitis media is specified at 0.1 in $\mathrm{M}_{\mathrm{QLS}}$ and only 137 Caucasian families (the reported ethnicity has been verified with AIMs) are included in the $\mathrm{M}_{\mathrm{QLS}}$ analysis. We also imputed the HapMap [28] CEU SNPs to identify potential associated variants that were not included in our SNP panel [29].

\section{Results}

The maximum LOD score of the NPL linkage analysis was $3.75\left(\mathrm{P}=1.6 \times 10^{-5}\right)$ at $110.5 \mathrm{cM}$ (corresponding to 
63.4 $\mathrm{Mb}$ in physical distance), when the marker-marker LD was modeled at either $r^{2}>0.5$ or $r^{2}>0.2$. This result supported significant evidence for linkage between the 19q region and COME/ROM (Figure 1). The LOD-1 support interval (the interval in which the LOD score is within 1 unit of its maximum, which is usually treated as a confidence region [30]) for the identified linkage was between $107.3 \mathrm{cM}$ and $111.1 \mathrm{cM}(61.6 \mathrm{Mb}$ and 63.8 $\mathrm{Mb}$ in physical distance). When the marker-marker LD was not modeled, the maximum LOD score was 4.41 at 109.4 cM. The large difference of the maximum LOD scores between the two models (with LD modeled vs. not modeled) reflects the inflation of linkage due to the unaccounted marker-marker LD among the dense SNPs [22].

When 90 families (65\% of total number of families) with complete parental data were included in the linkage analysis, the maximum LOD score was 2.85 . Note the other $35 \%$ of data contains additional linkage evidence that can be estimated as shown above [22]. Since the marker-marker LD does not influence the linkage analysis in $65 \%$ of the data even without modeling LD in the analysis [22], and our result provides a projected LOD score of 4.38 for the entire set of families for the hypothetical case when all 138 families have complete parental information, the identified linkage in the $19 \mathrm{q}$ region is further supported.

The maximum LOD score based upon parametric linkage analysis was 5.42 at $107.5 \mathrm{cM}$, corresponding to $\mathrm{P}=1.6 \times 10^{-5}$. For a sibling of an affected individual, the recurrence risk of COME/ROM attributable to the $19 \mathrm{q}$ locus is twice as high as the recurrence risk in the population.

No statistically significant $(\mathrm{P}<0.0003)$ association between any SNP and COME/ROM was identified (Figure 2). Using a Bonferroni correction, 1,091 SNPs requires a nominal significance level of $\mathrm{P}<4.6 \times 10^{-5}$. Since the number of independent SNPs should be less than 1,091 because of the LD between SNPs, we estimated the number of independent SNPs by pruning pairwise LD between SNPs. There are 216 SNPs that are in approximate linkage disequilibrium with each other

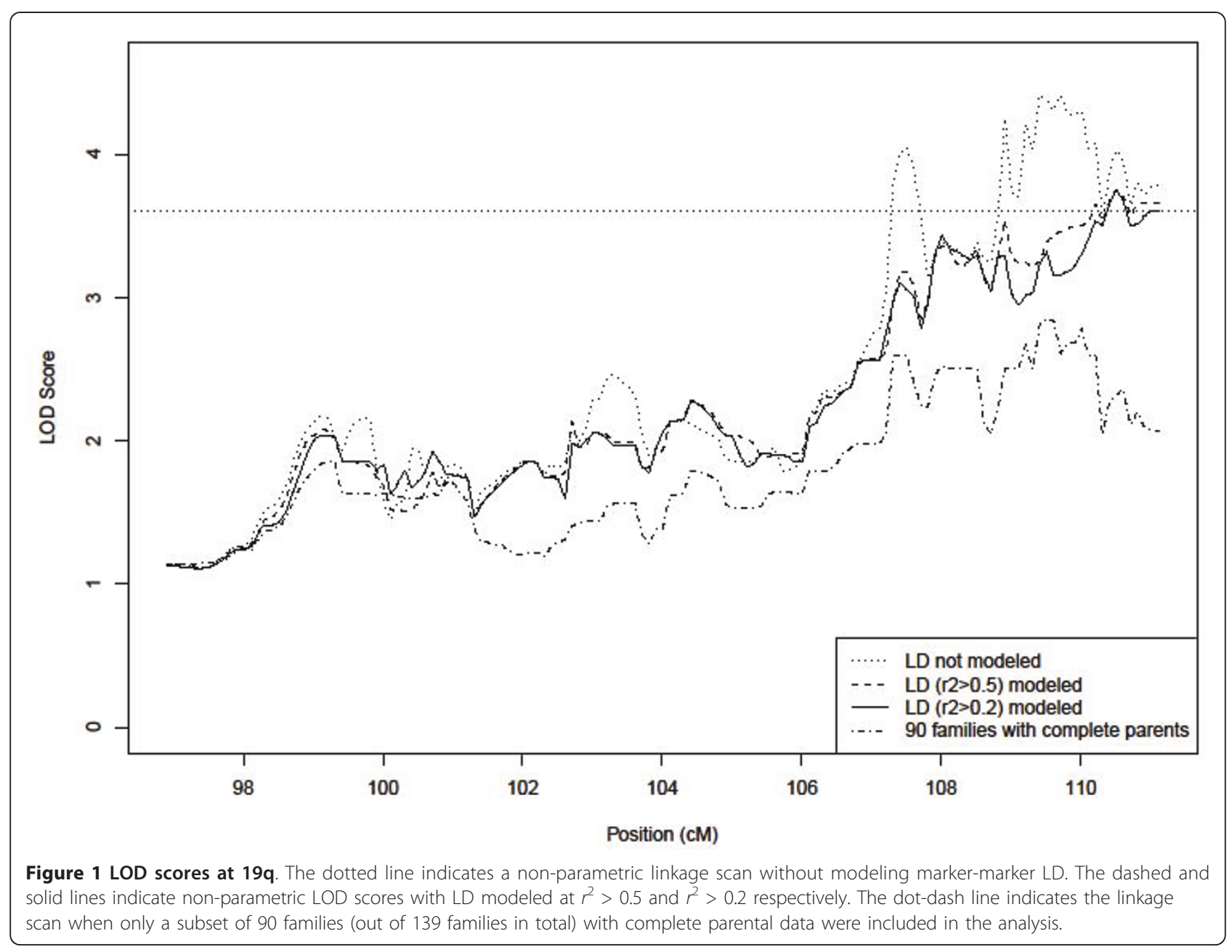



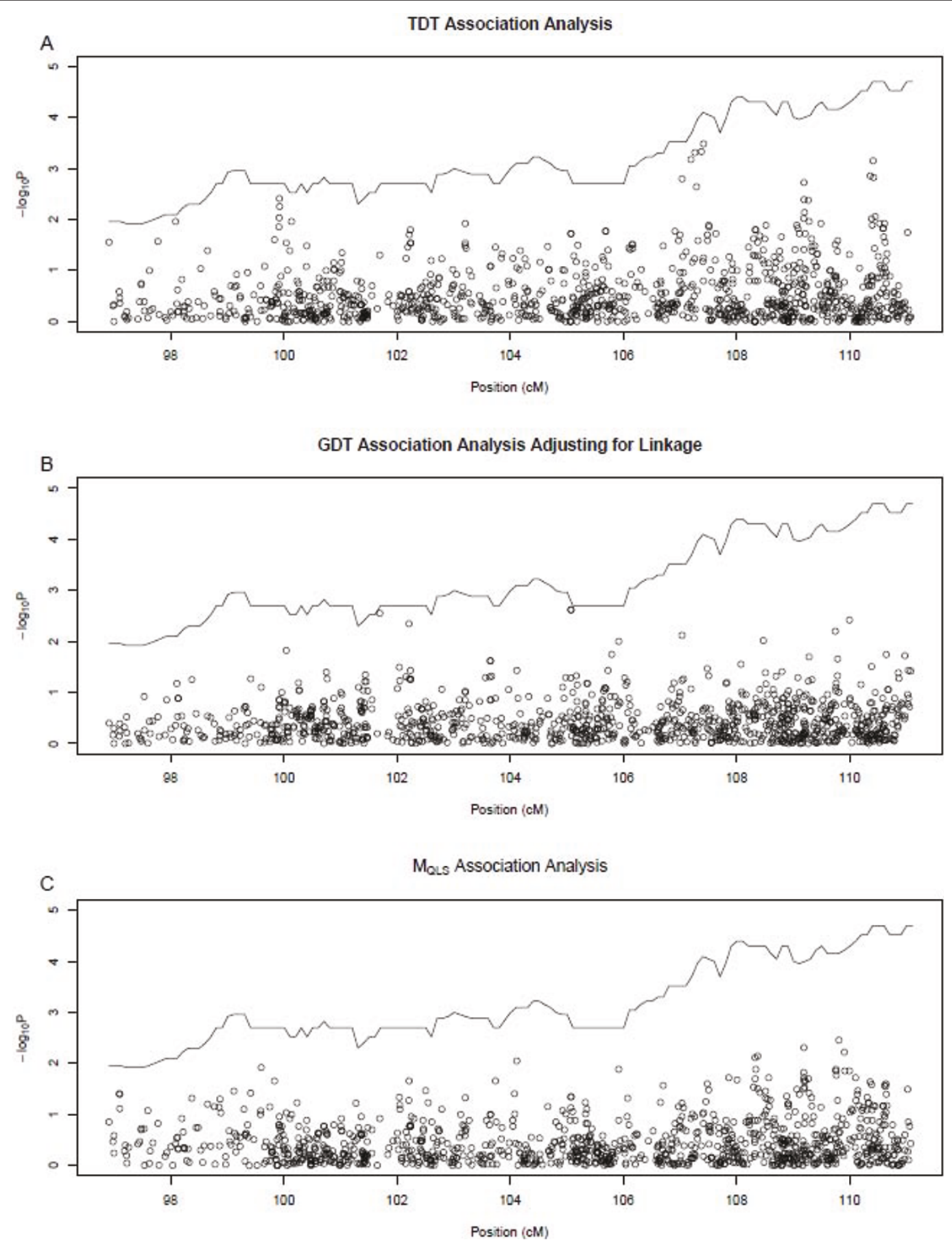

Figure 2 P values of association from two association tests: A. TDT, B. GDT, C. MQLS. P values in - $\log _{10}$ scale are represented by circles. The solid line indicates $p$ values of non-parametric LOD scores with LD modeled at $r^{2}>0.2$.

$\left(\mathrm{r}^{2}<0.1\right)$, and a Bonferroni correction based on 216 SNPs gives a nominal significance level of $\mathrm{P}<0.00023$. None of the observed associations reach either level of significance.
The five strongest associations identified through the TDT family-based association analyses (P value $<0.001$ ) all fall in the LOD-1 support interval. In contrast, none of the family-based GDT or $\mathrm{M}_{\mathrm{QLS}}$ analyses yielded 
significant evidence of association $(\mathrm{P}<0.001)$. The strongest association detected by TDT reflects the inflation of the statistics due to linkage in the region, rather than by association at a single variant [25]. Using GDT analysis, the strongest association $(\mathrm{P}=0.0024)$ falls outside of the LOD-1 support interval.

Rare variants in this region of $19 \mathrm{q}$ are much less represented than common variants in our SNP panel. Among all 1,091 SNPs, there are only 81 SNPs with a minor allele frequency less than $5 \%$. The lack of significant association is consistent with evidence that linkage in the $19 \mathrm{q}$ region is not due to common genetic variants.

\section{Discussion}

We extended our previously reported linkage analysis on chromosome 19q with dense SNP genotyping in the critical $5 \mathrm{Mb}$ region. Analyses of these additional data confirmed significant evidence supporting linkage in this region to COME/ROM, increasing the LOD score from 2.61 [14] to 3.75 at position $63.4 \mathrm{Mb}$. The SNP closest to D19S254 (62.359 Mb), the marker with the maximum LOD score of 2.61 in the original linkage scan [14], is rs810859 (62.358 Mb), and the LOD score at this SNP is 3.38 (with LD $\mathrm{r}^{2}>0.2$ modeled). The dense markers, as well as a larger sample size, have therefore helped improve the LOD score and localize the region of linkage. Additionally, parametric linkage analysis of our data suggests that for a sibling of an affected individual, the recurrence risk of COME/ROM that is due to this linkage region is twice as high as the recurrence risk in the population. Our analysis provides evidence that a COME/ROM susceptibility locus can be found within this region.

The LOD-1 support interval represents the telomeric region of chromosome 19. This region is high in gene content, containing over 90 known genes. Many of the genes in this region are zinc finger and zinc fingerrelated genes. Potential candidates for COME/ROM susceptibility include $Z N F 71$, an endothelial zinc finger gene induced by TNF- $\alpha$ [31], ZNF8, which represses BMP and FGFß pathways important during development \{Jiao, $2002 \# 32\}$, and ZNF304, which has been found to activate lymphocytes [32]. Other candidate genes in this region include members of the inflammasome protein complex, NLRP13, NLRP5 and NLRP8. Inflammasomes are key regulators of the innate immune response to harmful exogenous or endogenous stimuli $[33,34]$ Alpha-1-B glycoprotein (A1BG) is similar in sequence to proteins in the immunoglobulin supergene family, and has been associated with severe inflammation [35]. Chromatin modifying protein 2A (CHMP2A) is part of the chromatin-modifying protein/charged multivesicular body protein (CHMP) involved in surface receptor degradation and formation of endocytic bodies
[36]. Clearly, there are many genes within the linkage peak region on chromosome 19 with biological functions of potential relevance to COME/ROM susceptibility. The actions of multiple genes in this region, rather than a single gene, on COME/ROM risk cannot be excluded.

\section{Conclusion}

In summary, we confirmed linkage of COME/ROM to chromosome 19q in a family based population with dense genotyping of a previously identified $5 \mathrm{Mb}$ region. The lack of significant association with common variants in this region suggests that the observed significant linkage may be due to rare variants. Numerous studies have provided evidence that rare variant are involved in the etiology of complex traits (Liu and Leal, 2010). Further examination of the 19q region in COME/ROM susceptibility by next-generation sequencing of the region may be required in order to detect rare variants that may have novel and functionally significant effects. These studies are currently underway to determine the COME/ROM susceptibility gene in this region.

\section{Acknowledgements}

We thank the families for their participation, and the recruitment team: Donna Brauer, Karen Savonna, Ruth Selvius, Ann Brauti, Cynthia Roh, Michele Bochert, Jennifer Palmer, Kendra Herrell, Judy Monroe, Norrita Rech, Kim Canfield, Heather Nelson, and JoAnn Knox. Thanks also to Kathleen Day and Pamela Hicks for technical assistance, and Corinne Boehm and colleagues at the Center for Inherited Disease Research (CIDR). We thank one reviewer for valuable input that improved the article. This work was supported by National Institutes of Health grant DC003166 and DC003166-S1 (KAD). Genotyping services were provided by CIDR. CIDR is funded through a federal contract from the National Institutes of Health to The Johns Hopkins University, contract number HHSN268200782096C.

\section{Author details}

'Center for Public Health Genomics, University of Virginia, Charlottesville, VA 22908, USA. ${ }^{2}$ Department of Public Health Sciences, University of Virginia, Charlottesville, VA 22908, USA. ${ }^{3}$ Department of Biology, University of Virginia, Charlottesville, VA 22908, USA. ${ }^{4}$ Department of Medicine, University of Virginia, Charlottesville, VA 22908, USA. ${ }^{5}$ Department of Biochemistry and Molecular Genetics, University of Virginia, Charlottesville, VA 22908, USA. ${ }^{6}$ Department of Otolaryngology, University of Minnesota, Minneapolis MN 55455, USA.

\section{Authors' contributions}

WMC, MMS, KAD and EKA drafted the manuscript. SSR and KAD conceived of the family-based study, and KAD oversaw recruitment. MMS, JCM, SSR, and KAD participated in the design of the linkage follow-up study. JCM was responsible for SNP selection. MMS oversaw and coordinated molecular genetic analyses. JCM and XH conducted quality control procedures on genotype data. WMC and FC performed the statistical analysis. All authors read and approved the final manuscript.

Received: 31 March 2011 Accepted: 26 September 2011 Published: 26 September 2011

\section{References}

1. Grevers $\mathrm{G}$ : Challenges in reducing the burden of otitis media disease: an ENT perspective on improving management and prospects for prevention. Int J Pediatr Otorhinolaryngol 2010, 74(6):572-577. 
2. Johnston LC, Feldman HM, Paradise $J$, Bernard BS, Colborn DK, Casselbrant ML, Janosky JE: Tympanic membrane abnormalities and hearing levels at the ages of 5 and 6 years in relation to persistent otitis media and tympanostomy tube insertion in the first 3 years of life: a prospective study incorporating a randomized clinical trial. Pediatrics 2004, 114(1):e58-67.

3. Daly KA, Hunter LL, Levine SC, Lindgren BR, Giebink GS: Relationships between otitis media sequelae and age. Laryngoscope 1998, 108(9):1306-1310.

4. Harsten G, Prellner K, Heldrup J, Kalm O, Kornfalt R: Recurrent acute otitis media. A prospective study of children during the first three years of life. Acta Otolaryngol 1989, 107(1-2):111-119.

5. Teele DW, Klein JO, Rosner B: Epidemiology of otitis media during the first seven years of life in children in greater Boston: a prospective, cohort study. J Infect Dis 1989, 160(1):83-94.

6. Teele DW, Klein JO, Rosner BA: Epidemiology of otitis media in children. Ann Otol Rhinol Laryngol Suppl 1980, 89(3 Pt 2):5-6.

7. De Melker RA, Burke PD: Epidemiology of otitis media and the role of the general practitioner in management. Fam Pract 1988, 5(4):307-313.

8. Daly KA, Rich SS, Levine S, Margolis RH, Le CT, Lindgren B, Giebink GS: The family study of otitis media: design and disease and risk factor profiles. Genet Epidemiol 1996, 13(5):451-468.

9. Kvaerner KJ, Tambs K, Harris JR, Magnus P: Distribution and heritability of recurrent ear infections. Ann Otol Rhinol Laryngol 1997, 106(8):624-632.

10. Casselbrant ML, Mandel EM, Fall PA, Rockette HE, Kurs-Lasky M, Bluestone CD, Ferrell RE: The heritability of otitis media: a twin and triplet study. JAMA 1999, 282(22):2125-2130.

11. Rovers M, Haggard M, Gannon M, Koeppen-Schomerus G, Plomin R: Heritability of symptom domains in otitis media: a longitudinal study of 1,373 twin pairs. Am J Epidemio/ 2002, 155(10):958-964.

12. Kvestad E, Kvaerner KJ, Roysamb E, Tambs K, Harris JR, Magnus P: Otitis media: genetic factors and sex differences. Twin Res 2004, 7(3):239-244.

13. Kvestad E, Kvaerner KJ, Roysamb E, Tambs K, Harris JR, Magnus P: Recurrent otitis media and tonsillitis: common disease predisposition. Int J Pediatr Otorhinolaryngol 2006, 70(9):1561-1568.

14. Daly KA, Brown WM, Segade F, Bowden DW, Keats BJ, Lindgren BR, Levine SC, Rich SS: Chronic and recurrent otitis media: a genome scan for susceptibility loci. Am J Hum Genet 2004, 75(6):988-997.

15. Casselbrant ML, Mandel EM, Jung J, Ferrell RE, Tekely K, Szatkiewicz JP, Ray A, Weeks DE: Otitis media: a genome-wide linkage scan with evidence of susceptibility loci within the $17 q 12$ and $10 q 22.3$ regions. BMC Med Genet 2009, 10:85.

16. Segade F, Daly KA, Allred D, Hicks PJ, Cox M, Brown M, Hardisty-Hughes RE, Brown SD, Rich SS, Bowden DW: Association of the FBXO11 gene with chronic otitis media with effusion and recurrent otitis media: the Minnesota COME/ROM Family Study. Arch Otolaryngol Head Neck Surg 2006, 132(7):729-733

17. Gunderson KL, Kruglyak S, Graige MS, Garcia F, Kermani BG, Zhao C, Che D, Dickinson T, Wickham E, Bierle J, et al: Decoding randomly ordered DNA arrays. Genome Res 2004, 14(5):870-877.

18. Wigginton JE, Abecasis GR: PEDSTATS: descriptive statistics, graphics and quality assessment for gene mapping data. Bioinformatics 2005, 21(16):3445-3447.

19. O'Connell JR, Weeks DE: PedCheck: a program for identification of genotype incompatibilities in linkage analysis. Am J Hum Genet 1998, 63(1):259-266.

20. Abecasis GR, Cherny SS, Cookson WO, Cardon LR: Merlin-rapid analysis of dense genetic maps using sparse gene flow trees. Nat Genet 2002, 30(1):97-101.

21. Kong A, Cox NJ: Allele-sharing models: LOD scores and accurate linkage tests. Am J Hum Genet 1997, 61(5):1179-1188.

22. Abecasis GR, Wigginton JE: Handling marker-marker linkage disequilibrium: pedigree analysis with clustered markers. Am J Hum Genet 2005, 77(5):754-767.

23. Li M, Boehnke $M$, Abecasis GR: Joint modeling of linkage and association: identifying SNPs responsible for a linkage signal. Am J Hum Genet 2005, 76(6):934-949.

24. Spielman RS, McGinnis RE, Ewens WJ: Transmission test for linkage disequilibrium: the insulin gene region and insulin-dependent diabetes mellitus (IDDM). Am J Hum Genet 1993, 52(3):506-516.
25. Chen WM, Manichaikul A, Rich SS: A generalized family-based association test for dichotomous traits. Am J Hum Genet 2009, 85(3):364-376.

26. Thornton T, McPeek MS: Case-control association testing with related individuals: a more powerful quasi-likelihood score test. Am J Hum Genet 2007, 81(2):321-337.

27. Chen WM, Deng HW: A general and accurate approach for computing the statistical power of the transmission disequilibrium test for complex disease genes. Genet Epidemiol 2001, 21(1):53-67.

28. International HapMap C: A haplotype map of the human genome. Nature 2005, 437(7063):1299-1320.

29. Li Y, Willer C, Sanna S, Abecasis G: Genotype imputation. Annu Rev Genomics Hum Genet 2009, 10:387-406.

30. Kruglyak L, Lander ES: High-resolution genetic mapping of complex traits. Am J Hum Genet 1995, 56(5):1212-1223.

31. Mataki C, Murakami T, Umetani M, Wada Y, Ishii M, Tsutsumi S, Aburatani H, Hamakubo T, Kodama T: A novel zinc finger protein mRNA in human umbilical vein endothelial cells is profoundly induced by tumor necrosis factor alpha. Journal of atherosclerosis and thrombosis 2000, 7(2):97-103.

32. Sabater L, Ashhab Y, Caro P, Kolkowski EC, Pujol-Borrell R, Dominguez O: Identification of a KRAB-containing zinc finger protein, ZNF304, by AUmotif-directed display method and initial characterization in lymphocyte activation. Biochemical and biophysical research communications 2002, 293(3):1066-1072.

33. Schroder K, Tschopp J: The inflammasomes. Cell 2010, 140(6):821-832.

34. Taxman DJ, Huang MT, Ting JP: Inflammasome inhibition as a pathogenic stealth mechanism. Cell host \& microbe 2010, 8(1):7-11.

35. Valletta EA, Rigo A, Bonazzi L, Zanolla L, Mastella G: Modification of some markers of inflammation during treatment for acute respiratory exacerbation in cystic fibrosis. Acta Paediatr 1992, 81(3):227-230.

36. Morita E, Colf LA, Karren MA, Sandrin V, Rodesch CK, Sundquist WI: Human ESCRT-III and VPS4 proteins are required for centrosome and spindle maintenance. Proceedings of the National Academy of Sciences of the United States of America 2010, 107(29):12889-12894

\section{Pre-publication history}

The pre-publication history for this paper can be accessed here: http://www.biomedcentral.com/1471-2350/12/124/prepub

doi:10.1186/1471-2350-12-124

Cite this article as: Chen et al:: Significant linkage at chromosome 19q for otitis media with effusion and/or recurrent otitis media (COME/ ROM). BMC Medical Genetics 2011 12:124.

\section{Submit your next manuscript to BioMed Central and take full advantage of:}

- Convenient online submission

- Thorough peer review

- No space constraints or color figure charges

- Immediate publication on acceptance

- Inclusion in PubMed, CAS, Scopus and Google Scholar

- Research which is freely available for redistribution

Submit your manuscript at www.biomedcentral.com/submit
C Biomed Central 